\title{
Testing pigeon memory in a change detection task
}

\author{
Anthony A. Wright \\ University of Texas Health Science Center, Houston, Texas \\ JefFrey S. Katz and John MagnotTi \\ Auburn University, Auburn, Alabama \\ AND \\ L. Caitlin Elmore, Stephanie BabB, ANd Sarah Alwin \\ University of Texas Health Science Center, Houston, Texas
}

\begin{abstract}
Six pigeons were trained in a change detection task with four colors. They were shown two colored circles on a sample array, followed by a test array with the color of one circle changed. The pigeons learned to choose the changed color and transferred their performance to four unfamiliar colors, suggesting that they had learned a generalized concept of color change. They also transferred performance to test delays several times their 50msec training delay without prior delay training. The accurate delay performance of several seconds suggests that their change detection was memory based, as opposed to a perceptual attentional capture process. These experiments are the first to show that an animal species (pigeons, in this case) can learn a change detection task identical to ones used to test human memory, thereby providing the possibility of directly comparing short-term memory processing across species.
\end{abstract}

Memory typically requires storage, processing, and retrieval of information. Although memory research has been avidly pursued for more than a century, characteristics of different kinds of memory continue to be discovered at an ever increasing pace. Short-term memory is the foundation of long-term memory but is typically thought to be limited in terms of storage capacity or durability. One of the most popular procedures for studying shortterm memory in humans has been change detection. For example in one change detection study, several objects (e.g., colored squares) were presented in a sample array, and after a short delay, subjects identified which object in a test array had changed (e.g., Eng, Chen, \& Jiang, 2005). Although animals have not previously been tested in change detection, this procedure should be eminently suitable for testing animal short-term memory and making direct species comparisons, because change detection does not depend on verbal memory (e.g., Alvarez \& Cavanagh, 2004; Luck \& Vogel, 1997).

Change detection differs from other animal memory testing procedures, such as the matching-to-sample (MTS) or sameldifferent (S/D) procedure. Human experiments have shown change detection to be fundamentally different from visual search, which is equivalent to a delayed MTS procedure (Eng et al., 2005). Rensink (2002) reviewed change detection and compared it with S/D performance, saying that "the two [change detection and S/D] are not the same" and that change detection is a temporal transformation resulting in dynamic change, whereas $\mathrm{S} / \mathrm{D}$ involves "no notion of transformation" (p. 250). In change detection, transformation depends on recognizing that the two object arrays (i.e., sample and test arrays) are related. Perhaps critical to this concept of transformation is that the test objects are presented in the same locations as the sample objects. Same locations provide a no-change context, so that the two object arrays can be more easily related and the concept of transformation and change may be more easily learned.

In the experiments reported in this article, we trained and tested pigeons in a change detection task that required them to detect the changed item in a test display. Our change detection procedure was modeled after that used by Eng et al. (2005), and similar procedures have been used by other researchers to test human memory (e.g., Hollingworth, 2007; Mondy \& Coltheart, 2006; Smilek, Eastwood, \& Merikle, 2000). The procedure of identifying which item has changed yields results (e.g., visual working memory capacity) similar to those for procedures of reporting whether or not a change has occurred (cf. Alvarez \& Cavanagh, 2004). A consideration for adopting the procedure requiring pigeons to respond to the changed item was that animals generally attend better to stimuli they touch or peck and, thereby, learn more rapidly (e.g., Harrison, Iversen, \& Pratt, 1977; Stollnitz, 1965; Wright, Shyan, \& Jitsumori, 1990). In addition, as Green and Swets (1966) pointed out more than 40 years

A. A.Wright, anthony.a.wright@uth.tmc.edu; J. S. Katz, katzjef@auburn.edu 
ago, forced choice psychophysical procedures (e.g., in this case, peck the changed item) minimize response biases better, relative to yes/no psychophysical procedures (e.g., in this case, respond "change" or "no-change").

\section{EXPERIMENT 1}

We began training pigeons with a simple task of identifying which of two colored circles changed color. We presented two-item sample arrays for $5 \mathrm{sec}$, followed $50 \mathrm{msec}$ later by a testing display with one of the sample items changing color. We used four training colors, and following acquisition, we tested the pigeons with four novel colors.

\section{Method}

\section{Subjects}

Six White Carneaux pigeons, 2-7 years old, from the Palmetto Pigeon Plant (Sumter, SC) participated in the experiment. Three pigeons had prior experience in an unrelated task (S/D) and a different testing chamber. Testing was conducted 5 days per week. The pigeons were maintained at $85 \%$ of their free-feeding weights, with free access to grit and water in their individual home cages. A 14:10-h light:dark cycle was maintained in the room containing the home cages.

\section{Apparatus}

The pigeons were tested in identical $(35.9 \mathrm{~cm}$ wide $\times 45.7 \mathrm{~cm}$ deep $\times 51.4 \mathrm{~cm}$ high) custom-designed wooden test chambers with exhaust fans, custom wooden grain deliveries centered below 17-in. Eizo T550 color monitors $(800 \times 600$ pixels $)$, and infrared touch screens (Carroll Touch, Round Rock, TX). Houselights (Chicago Miniature 1829, $24 \mathrm{~V}$ ) were located in the center of the ceilings and were illuminated during intertrial intervals (ITIs).

\section{Stimuli}

The stimuli were color circles $(1.50 \mathrm{~cm})$ shown on an invisible $4 \times 4$ matrix $(9 \mathrm{~cm}$ horizontal, $7 \mathrm{~cm}$ vertical). PaintShop Pro RGB values for the training stimuli were the following: red, 255, 0, 0; aqua, 0, 255, 255; yellow, 255, 255, 0; and purple, 180, 0, 255. PaintShop Pro RGB values for the transfer stimuli were the following: blue, 0, 0, 255; green, 0, 255, 0; magenta, 255, 0, 255; and orange, $255,128,0$. The stimuli were not equated for the pigeon's photopic sensitivity or for metameric hue differences. An attempt could have been made to equate brightness (e.g., Blough, 1957) and hue changes (e.g., Wright, 1972, 1978) with these broadband stimuli for pigeons, but such manipulations are seldom done in change detection experiments, even for the far easier case involving human participants.

\section{Procedure}

Preliminary training (6-12 sessions) involved hopper training, autoshaping, and successive-approximations training to brightness changes (bright to dim or dim to bright) of a single achromatic (i.e., white) circle (depending on the subject). Once the pigeons were reliably pecking an achromatic circle following a brightness change, training in the change detection task began. The 3 pigeons with previous experience in another experimental task were placed immediately into the change detection task.

Figure 1 shows an example of two change detection trials. Trials began with a 5-sec, sample array presentation of two circles of different colors (quasirandomly selected from aqua, red, yellow, and purple) at 2 positions on the 16-position matrix. The sample array disappeared (delay) for $50 \mathrm{msec}$, followed by a test array presentation. The test array consisted of two circles in the same sample array positions, with one circle changed in color (to a color different from both sample array colors). A response to the changed-color test circle was correct and was followed by $2.5-4.4 \mathrm{sec}$ of mixed grain reinforcement (depending on the individual subject) and then a 15-sec ITI. An incorrect response was not reinforced and was followed by the ITI. The houselight was illuminated only during the ITI and was extinguished $300 \mathrm{msec}$ prior to the beginning of the next trial. On Session 2, incorrect responses were followed by a correction procedure consisting of a 15 -sec time-out, the 15-sec ITI, and a repeat of the trial. (Two pigeons [P8040 and P8893] had a different correction procedure for their first 15 sessions; in this correction procedure, the changed object changed back and forth between the sample and test color every $3 \mathrm{sec}$ until it was pecked, whereas pecks to the incorrect object had no consequence.)

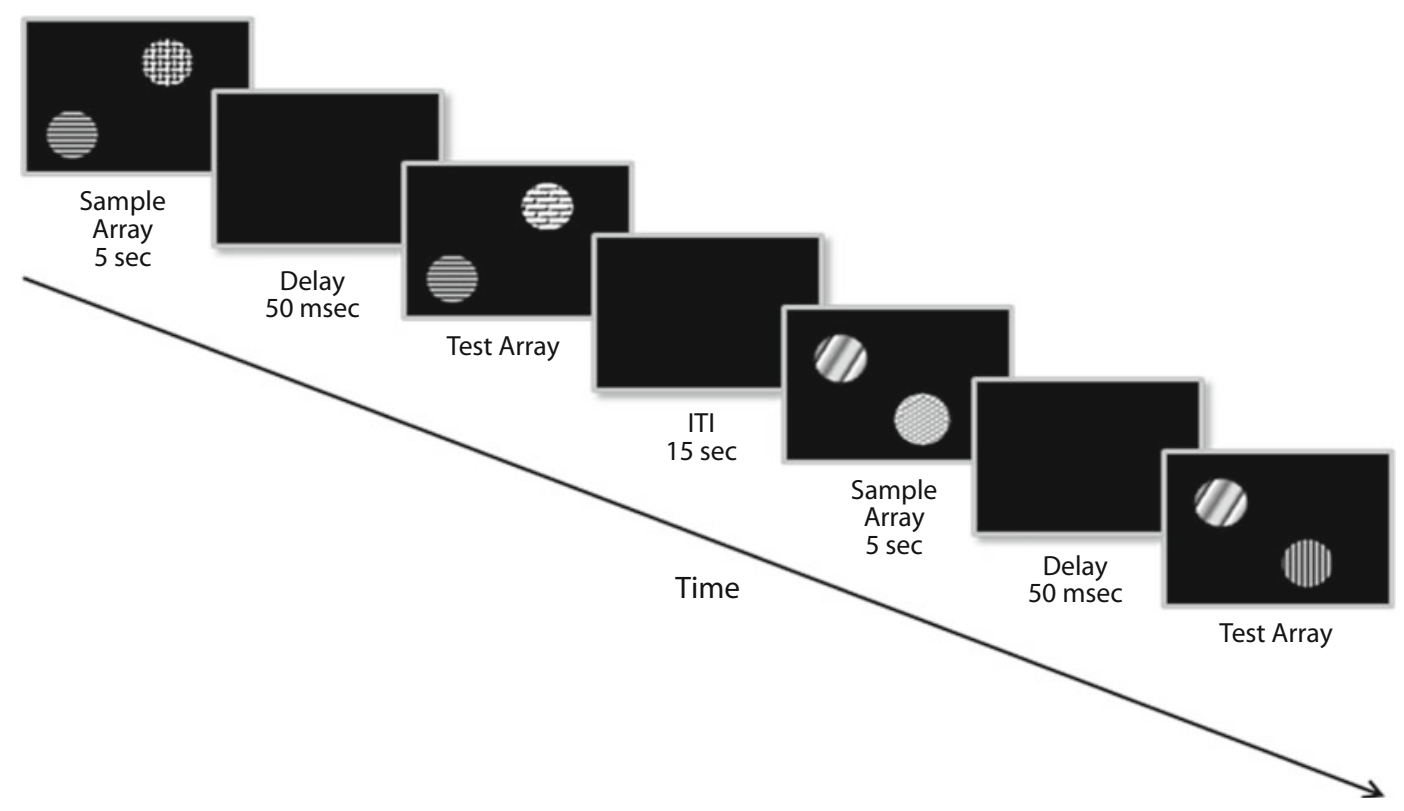

Figure 1. Examples of two change detection trials, showing a change in one object from the sample array to the test array. The actual changes were changes in object color, which are depicted here as pattern changes. 
Change detection training sessions were 96 trials. Frequencies of the four training colors in sample arrays were counterbalanced as the sample stimuli and the changed color within each session. The possible locations of different colors of sample pairs were counterbalanced across sessions. Training continued until a criterion of three sessions (or two consecutive sessions) of $\geq 80 \%$ correct. Following criterion performance, the correction procedure was removed, and training continued until the criterion was reestablished on a single session. This noncorrection procedure criterion was followed by color transfer testing.

Transfer. The pigeons were tested in six consecutive color transfer sessions consisting of 84 training trials with the four training colors and 12 transfer trials with four new transfer colors. Each of the four transfer stimuli appeared in the sample array on 6 trials, and each transfer color was the changed to stimulus on 3 out of the 6 trials in which it did not appear in the sample array. Correct performance on transfer trials was reinforced in the same way as on training trials.

\section{Results}

\section{Acquisition}

Learning functions. Figure 2 shows the acquisitions for the 6 pigeons trained in this change detection task. As a group, performance rose rapidly over the first 17-20 sessions, leveled off at about $75 \%$ correct, and thereafter rose gradually to eventually meet the $80 \%$ accuracy criterion.

Sample pecking. The pigeons often pecked the samples during the 5-sec presentation of the sample display. We analyzed whether pecking a particular sample object might influence their subsequent choice response. For example, if they were pecking the sample object that was not programmed to change, they might continue pecking this object when the test display appeared. Figure 3 shows the mean performance for the last three acquisition sessions (criterion session plus the previous two sessions) for all the pigeons. Accuracy and frequency are shown as functions of which, if any, sample object was last pecked. Figure 3 shows that the pigeons were more accurate when they pecked sample objects that would change (correctobject peck; $85 \%$ ) than when they pecked sample objects that would not change (incorrect-object peck; 69.6\%), as shown by a one-way ANOVA of peck type on peck accuracy $\left[F(2,15)=5.963, p=.012, \eta_{\mathrm{p}}^{2}=.44\right.$; Tukey post hoc test, $p=.01]$.

In terms of mean frequencies of peck types (right-hand ordinate), pigeons pecked sample object locations more often than they did not, as shown by a one-way ANOVA of peck type on mean peck frequency per session $[F(2,15)=$ $6.48, p<.01, \eta_{\mathrm{p}}^{2}=.46$; Tukey post hoc tests, $\left.p \mathrm{~s}<.025\right]$. Sample peck frequencies were equivalent for the to-bechanged and not-to-be-changed objects $(p>.05)$, as would be expected because there was no information during the sample display as to which object would change.

Sample pecking and acquisition. A session-bysession analysis according to which stimulus in the sample array was last pecked is shown in Figure 4 for consecutive acquisition sessions (28) in which all the subjects participated. The lower portion of Figure 4 shows the cumulative frequency of the three peck types. A two-way repeated measures ANOVA showed a session $\times$ peck type interaction $\left[F(54,270)=5.7, p<.001, \eta_{\mathrm{p}}^{2}=.53\right]$, demonstrating that sample pecking was maintained as acquisition progressed. The linearity of the peck type cumulative functions show that sample pecking was maintained at a similar rate throughout acquisition. The major contributing factor to acquisition was improved performance (30\%) following pecks to the sample object that did not change. That is, the pigeons learned to switch to the object that had changed if they were pecking the incorrect (not-tobe-changed) object during the sample display presentation. This difference is supported by a two-way repeated measures ANOVA of session $\times$ peck type (correct-object peck, incorrect-object peck) that produced a significant interaction $\left[F(27,135)=1.80, p=.016, \eta_{\mathrm{p}}^{2}=.26\right]$.

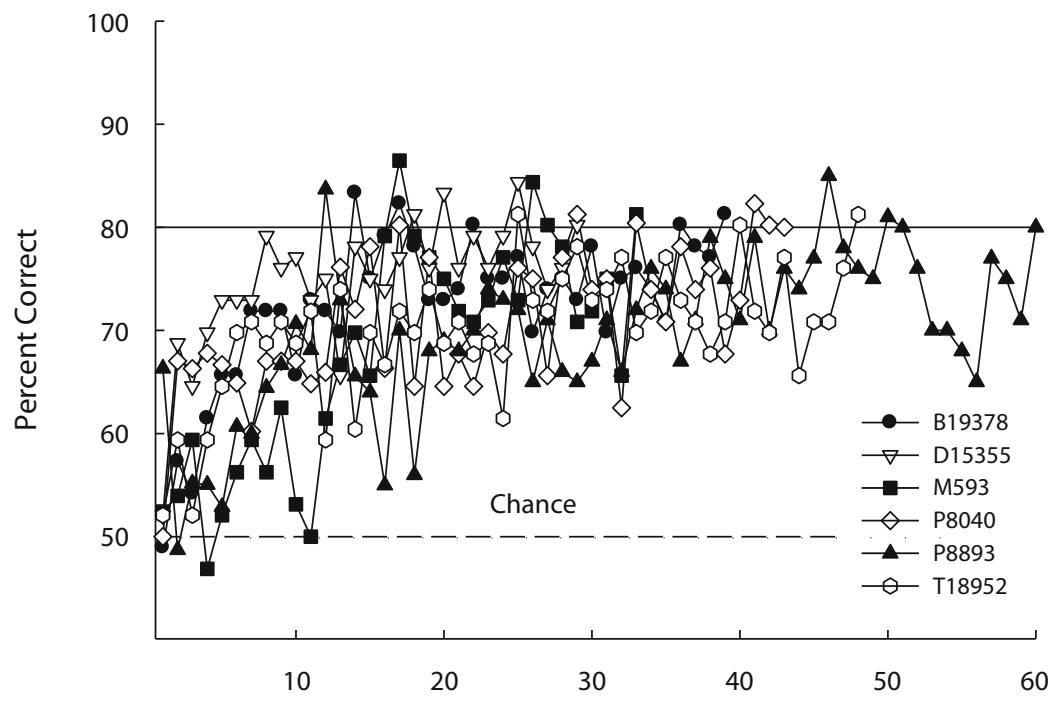

96-Trial Sessions

Figure 2. Learning functions of the color change detection task for 6 pigeons. 


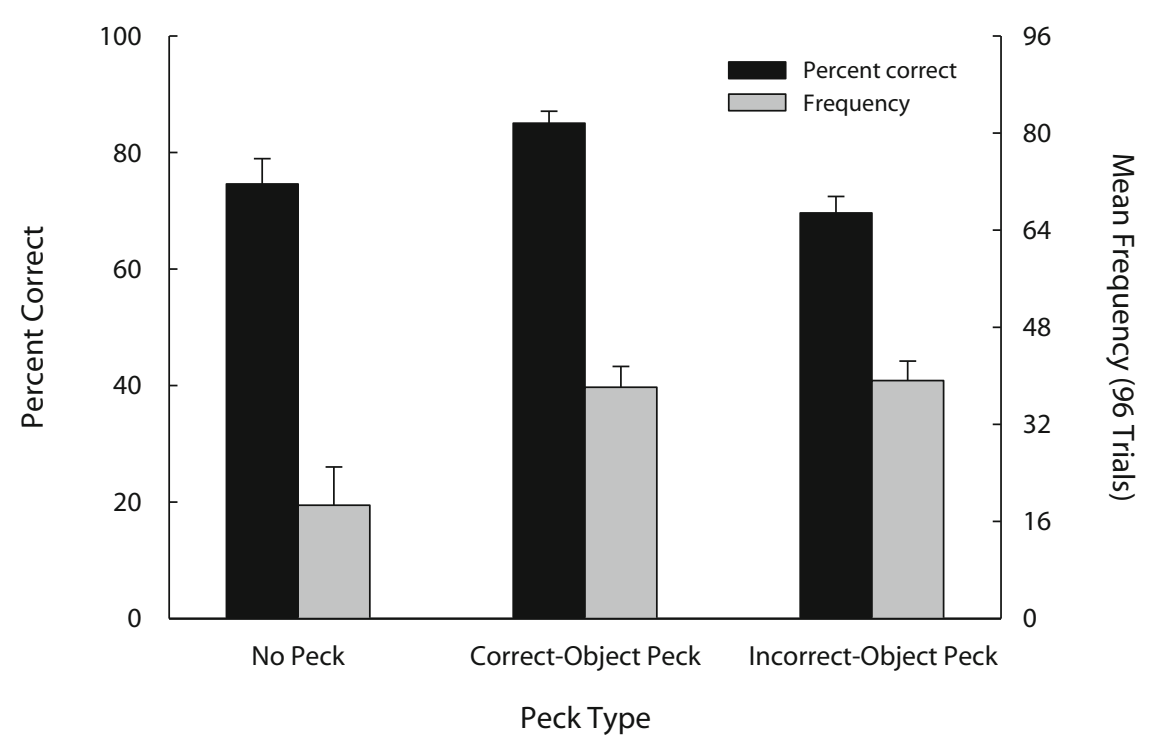

Figure 3. Mean accuracy (left axis) and frequency (right axis; out of 96 trials) for the final three acquisition sessions for which the sample array stimulus was last pecked (or none pecked) prior to the test array presentation. Error bars are standard errors of the means.

\section{Color Transfer}

Figure 5 shows the color transfer results for the 6 pigeons in this experiment. Mean accuracy $(68 \%)$ on transfer trials was well above chance performance $[50 \% ; t(5)=5.3, p<$ $.005]$. Transfer accuracy was not significantly different from baseline and was stable over the six transfer sessions, as was shown by a two-way repeated measures ANOVA of trial type (baseline, transfer) $\times$ session (1-6) on percentage correct that yielded no significant effects [trial type, $F(1,5)=5.5, p=.07$; session, $F(5,25)<1$; trial type $\times$ session, $F(5,25)=1.5, p=.24]$. Session 1 transfer performance was $73.7 \%$ and was significantly above chance $[t(5)=3.2, p<.05]$. Also, an analysis of peck proportions showed no aversion to pecking displays with novel colors, as compared with training colors $[F(1,5)=1.89$, $p>.05]$.

\section{Discussion}

The results from this experiment show that the pigeons learned change detection. They learned to correctly identify the changed object independently of any sample object responding. They learned to inhibit responding to the incorrect stimulus after the transition to the test display. They focused on the critical cue of change, as shown by

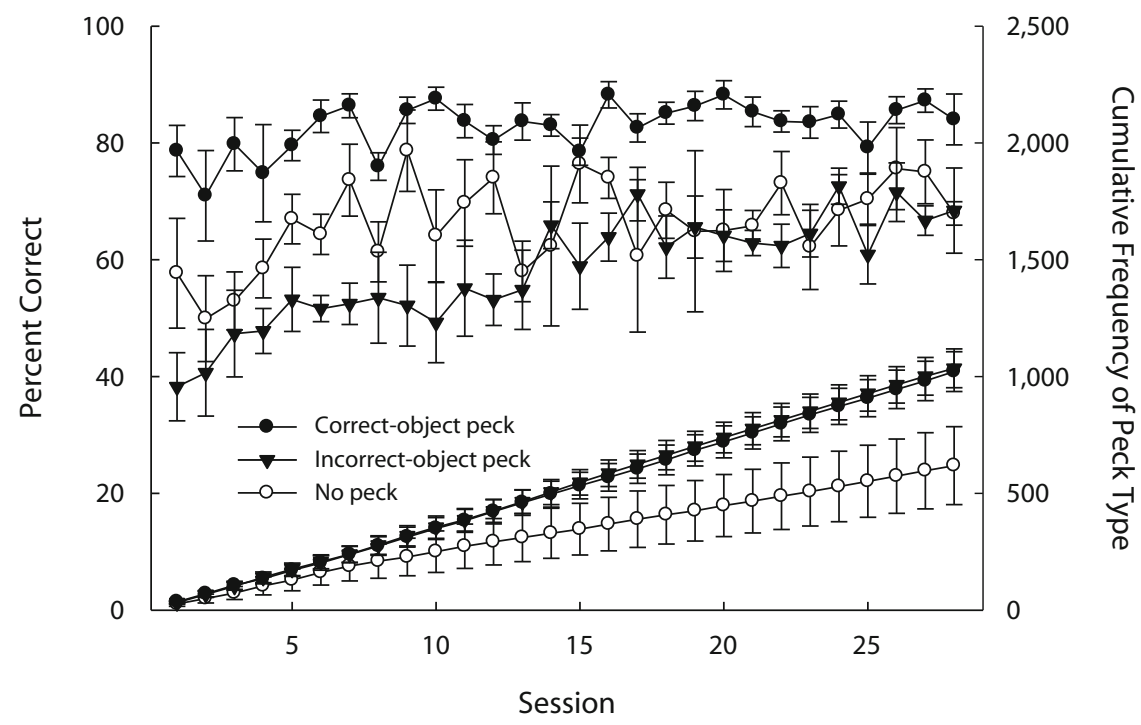

Figure 4. Mean accuracy (left axis) for the sample array stimulus last pecked (or none pecked) prior to the test array, along with the cumulative frequency (right axis) for the first 28 acquisition sessions. Error bars are standard errors of the means. 


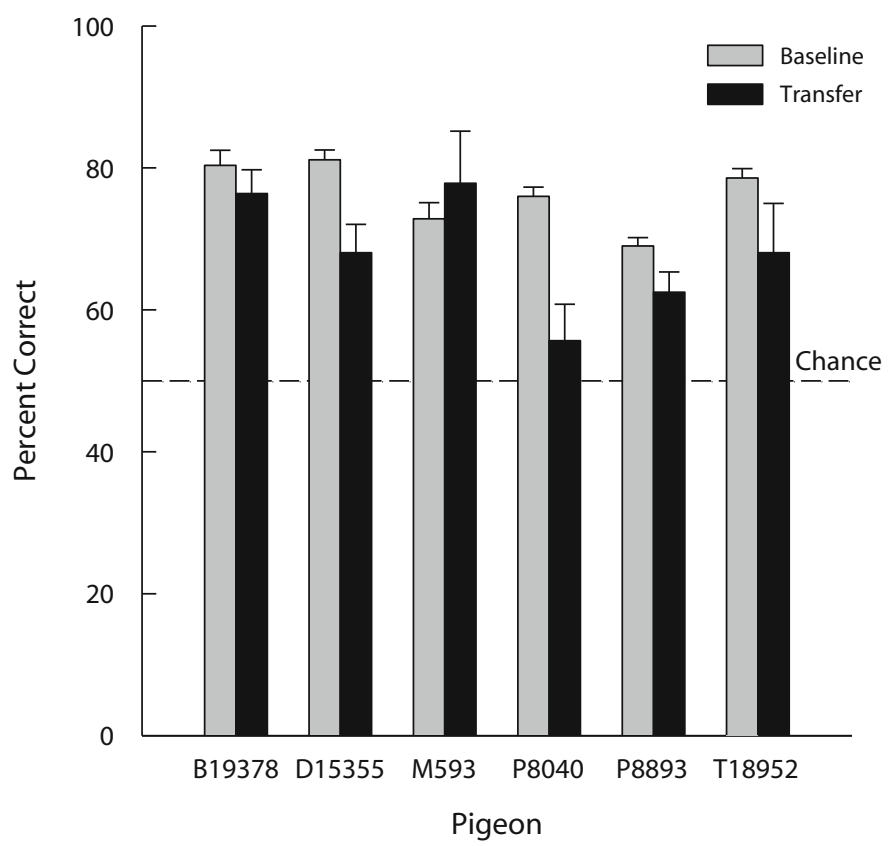

Figure 5. Transfer to the four novel colors and baseline accuracy during transfer testing for the 6 individual pigeons. Error bars are standard errors of the means.

transfer to new colors, in contrast to the pigeons' lack of transfer in other tasks. In MTS tasks with two to four training colors not unlike those used in this experiment, pigeons typically do not transfer to new colors (e.g., Carter \& Werner, 1978; Cumming \& Berryman, 1961; Farthing \& Opuda, 1974; Premack, 1978; Santi, 1982). This color transfer difference suggests a fundamental difference between change detection and other procedures, such as MTS and delayed MTS, that are often used to test pigeon memory and further suggests that in change detection, pigeons cue into the change in color, not associations linked to specific colors.

\section{EXPERIMENT 2}

Experiment 1 showed that pigeons learned a change detection task and transferred their performance to novel colors. Experiment 2 tested whether the change learned in Experiment 1 was based on the stimulus-driven automatic process of attentional capture that might have occurred to the abrupt color changes in the change detection task. Attentional capture involves an abrupt stimulus change (onset, offset, object novelty) and a mechanism that guides attention to the locus of change (e.g., Yantis, 1993). Since attentional capture is generic and not bound to any particular training stimuli, it could conceivably account for the learning and transfer shown in Experiment 1. The stimulus change in Experiment $1(50 \mathrm{msec})$ was within the range of attentional capture and sensory memory as studied in humans (e.g., Cusack, Lehmann, Veldsman, \& Mitchell, 2009; Pashler, 1988). Furthermore, pigeons have previously been shown to exhibit characteristics of attentional capture with abrupt color changes (Cook, Cavoto, Katz,
\& Cavoto, 1997). In order to test whether attentional capture might have played a role in the learning and transfer shown in Experiment 1, the pigeons were abruptly transferred to a series of mixed delays $(50,100,200,400,800$, $1,600,3,200$, and $6,400 \mathrm{msec}$ ), some of which would be well beyond the limits of human attentional capture. Our rationale was that if attentional capture was the controlling process, performance should decline precipitously at the limit of attentional capture. If, on the other hand, the pigeon's change detection was based on a short-term visual working memory process, there should be no such precipitous decline. Experiment 2 also tested whether the apparent critical cue of change would immediately transfer to longer delays without prolonged training over many sessions typically required with other pigeon memory tasks (e.g., S/D, MTS).

\section{Method}

\section{Subjects and Apparatus}

Five of the pigeons from Experiment 1 participated in Experiment 2. (One subject became ill just prior to this experiment.) The apparatus and stimuli were the same as those described in Experiment 1.

\section{Procedure}

Following the color transfer test, the training set was expanded from four to eight colors, using the previously tested colors. The eight colors and locations were counterbalanced as in Experiment 1. When performance was $\geq 80 \%$ correct with the correction procedure, followed by $\geq 80 \%$ correct without the correction procedure, the pigeons were tested for twenty-four 96-trial sessions with variable delays $(50,100,200,400,800,1,600,3,200$, and $6,400 \mathrm{msec})$ between the sample and test arrays. Each delay was tested on 12 random trials within each 96 -trial session. The 50 -msec delay provided a comparison with prior performance on the change detection 
task. Correct responses at all delays were reinforced, due to the large number of trials with longer testing delays and to avoid any association of extinction with longer delays.

\section{Results and Discussion}

Results from the variable retention delay test are shown in Figure 6. Delay performance was accurate and stable from the beginning of testing. A three-way repeated measures ANOVA for session ( 8 three-session blocks $) \times$ delay $\times$ peck type showed an effect of peck type $[F(2,8)=$ $\left.15.44, p<.01, \eta_{\mathrm{p}}^{2}=.794\right]$ and delay $[F(7,28)=7.64, p<$ $\left..01, \eta_{\mathrm{p}}^{2}=.656\right]$. There was no effect of session $[F(7,28)=$ $1.3, p>.05]$ and no interactions, showing good retention delay performance throughout the test. Mean first-trial performance for the seven novel delays $(100-6,400 \mathrm{msec})$ was $71.4 \%$ correct $(S E M=4.5)$ and well above chance $(50 \%)$ performance $[t(4)=4.74, p<.01]$. This successful transfer to longer delays suggests that what pigeons learn in the change detection task is qualitatively different from what they learn in S/D or MTS tasks that often require months of delay training.

The comparatively good delay performance and the absence of any precipitous decline in performance suggest that attentional capture was not the critical process in change detection. Indeed, instead of a decline in performance, change detection accuracy actually increased in the region (100-400 msec). Even for delays of 800 and $1,600 \mathrm{msec}$, performance was above $70 \%$ accuracy. The results of Experiment 2 suggest that the pigeons remembered the stimuli presented in the sample array for a considerable period of time, well beyond what might be expected from attentional capture. Thus, the results from this test suggest that these pigeons compared their memory of these stimuli with those of the test array.

\section{GENERAL DISCUSSION}

The experiments presented in this article show that pigeons learned change detection with four colored circles, transferred their performance to four new colors, and maintained accurate performance with delays of several seconds. Pigeons tended to respond to the sample array objects during the 5 -sec presentation time, which may have competed with noticing that the other object had changed color. Related to this attentional issue is that delays longer than the original $50-\mathrm{msec}$ training delay tended to create a pause in responding, because pigeons seldom peck in the absence of a stimulus. The pause in responding might be accompanied by the pigeons' being more attentive to the whole test array when it appeared and, thereby, noticing better which object changed color. The latter possibility is supported by the somewhat better performance at delays of 100 and $200 \mathrm{msec}$ than at the training delay, as shown in the variable retention delay function of Figure 6 .

The results from the experiments reported here show that pigeons can learn the change detection task. The pigeons' immediate transfer to new colors and longer delays suggests that they have a tendency for detecting change, generally. Establishing that a nonhuman animal such as the pigeon can learn change detection opens the possibility that many other animals, including monkeys, should be able to learn change detection-possibly even more readily than pigeons. Animal change detection studies of memory will be important because they provide direct species comparisons of how memory works (e.g., working memory capacity, location vs. object memory, interference) and allow manipulations of brain areas (e.g., recordings, lesions, neurotransmitters) critical for memory that are not possible with humans.

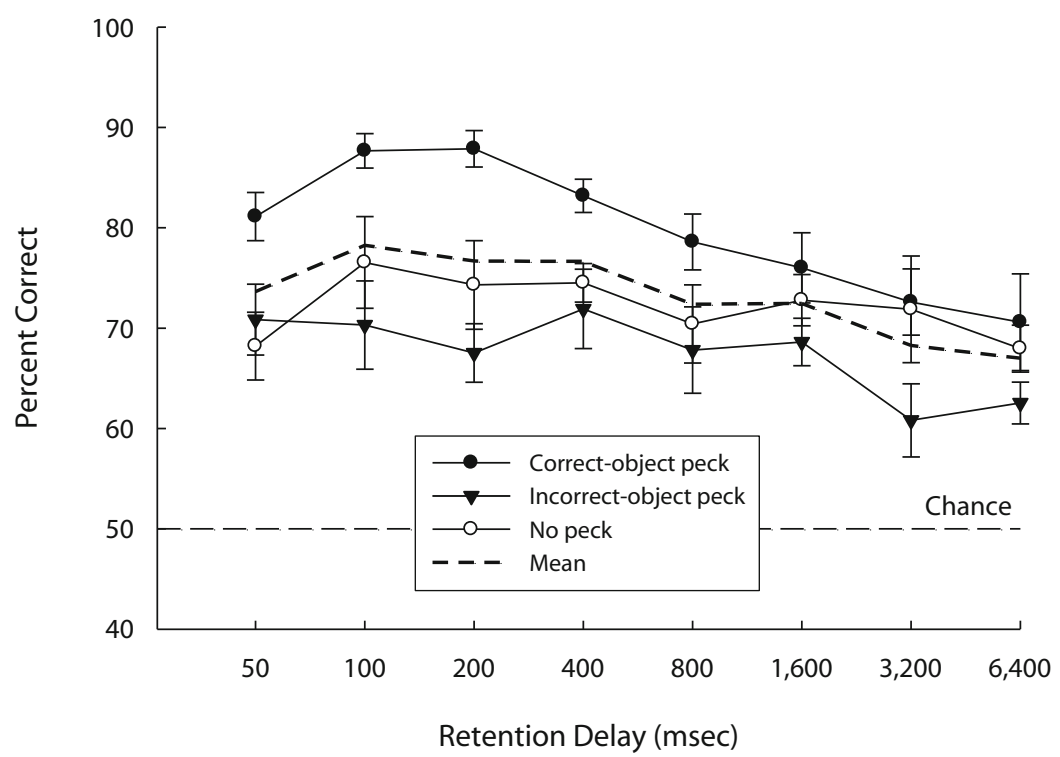

Figure 6. Mean accuracy during variable-delay retention testing for peck type (i.e., which sample array stimulus was last pecked or none pecked) during the sample array presentation. Error bars are standard errors of the means. 


\section{AUTHOR NOTE}

This research was supported by NIH Grant MH-072616. We thank Kent Bodily, Jacquelyne Rivera, Kelly Schmidtke, and Brad Sturz for their careful assistance with these experiments. Correspondence and reprint requests may be addressed to A. A. Wright, Department of Neurobiology and Anatomy, University of Texas Medical School at Houston, P.O. Box 20708, Houston, TX 77225, or J. S. Katz, Department of Psychology, Auburn University, 226 Thach Hall, Auburn, AL 36849 (e-mail: anthony.a.wright@uth.tmc.edu or katzjef@auburn.edu).

\section{REFERENCES}

Alvarez, G. A., \& Cavanagh, P. (2004). The capacity of visual short term memory is set both by visual information load and by the number of objects. Psychological Science, 15, 106-111. doi:10.1111/j.0963 $-7214.2004 .01502006 . x$

Blough, D. S. (1957). Spectral sensitivity in the pigeon. Journal of the Optical Society of America, 47, 827-833.

Carter, D. E., \& Werner, T. J. (1978). Complex learning and information processing by pigeons: A critical analysis. Journal of the Experi mental Analysis of Behavior, 29, 565-601. doi:10.1901/jeab.1978.29 $-565$

Cook, R. G., Cavoto, B. R., Katz, J. S., \& Cavoto, K. K. (1997). Pigeon perception and discrimination of rapidly changing texture stimuli. Journal of Experimental Psychology: Animal Behavior Processes, 23, 390-400. doi:10.1037/0097-7403.23.4.390

Cumming, W. W., \& Berryman, R. (1961). Some data on matching behavior in the pigeon. Journal of the Experimental Analysis of Behavior, 4, 281-284.

Cusack, R., Lehmann, M., Veldsman, M., \& Mitchell, D. J. (2009) Encoding strategy and not visual working memory capacity correlates with intelligence. Psychonomic Bulletin \& Review, 16, 641-647.

ENG, H. Y., CHEN, D., \& JIANG, Y. (2005). Visual working memory for simple and complex visual stimuli. Psychonomic Bulletin \& Review, 12, 1127-1133.

FARThing, G. W., \& OpUdA, M. J. (1974). Transfer of matching-tosample in pigeons. Journal of the Experimental Analysis of Behavior, 21, 199-213. doi:10.1901/jeab.1974.21-199

Green, D. M., \& Swets, J. A. (1966). Signal detection theory and psychophysics. New York: Wiley.

Harrison, J. M., Iversen, S. D., \& Pratt, S. R. (1977). Control of responding by location of auditory stimuli: Adjacency of sound and response. Journal of the Experimental Analysis of Behavior, 28, 243251. doi:10.1901/jeab.1977.28-243

Hollingworth, A. (2007). Object-position binding in visual memory for natural scenes and object arrays. Journal of Experimental Psychology: Human Perception \& Performance, 33, 31-47. doi:10.1037/0096 $-1523.33 .1 .31$

Luck, S. J., \& Vogel, E. K. (1997). The capacity of visual working memory for features and conjunctions. Nature, 390, 279-281. doi: $10.1038 / 36846$

Mondy, S., \& Coltheart, V. (2006). Phonological similarity effects on detecting change in simple arrays. Memory \& Cognition, 34, 17441753.

PASHler, H. (1988). Familiarity and visual change detection. Perception \& Psychophysics, 44, 369-378.

PremaCK, D. (1978). On the abstractness of human concepts: Why it would be difficult to talk to a pigeon. In S. H. Hulse, H. Fowler, \& W. K. Honig (Eds.), Cognitive processes in animal behavior (pp. 423 451). Hillsdale, NJ: Erlbaum.

RENSINK, R. A. (2002). Change detection. Annual Review of Psychology, 53, 245-277.

SANTI, A. (1982). Hue matching and hue oddity in pigeons: Is explicit training not to peck incorrect hue combinations a sufficient condition for transfer? Psychological Record, 32, 61-73.

SmileK, D., Eastwood, J. D., \& Merikle, P. M. (2000). Does unattended information facilitate change detection? Journal of Experimental Psychology: Human Perception \& Performance, 26, 480-487. doi:10.1037/0096-1523.26.2.480

STollnitz, F. (1965). Spatial variables, observing responses, and discrimination learning sets. Psychological Review, 72, 247-261.

Wright, A. A. (1972). Psychometric and psychophysical hue discrimination functions for the pigeon. Vision Research, 12, 1447-1464. doi:10.1016/0042-6989(72)90171-X

Wright, A. A. (1978). Construction of equal-hue discriminability scales for the pigeon. Journal of the Experimental Analysis of Behavior, 29 261-266. doi:10.1901/jeab.1978.29-261

Wright, A. A., Shyan, M. R., \& Jitsumori, M. (1990). Auditory samel different concept learning by monkeys. Animal Learning \& Behavior, 18, 287-294

Yantis, S. (1993). Stimulus-driven attentional capture. Current Directions in Psychological Science, 2, 156-161.

(Manuscript received August 5, 2009; revision accepted for publication October 30, 2009. ) 